\title{
Apexification of immature teeth using an apical matrix and MTA barrier material: Report of two
} cases.

\section{ABSTRACT}

Apexification is defined as a method to induce a calcified barrier at the root tip of a tooth with an open apex or to encourage the continued apical development of an incomplete root in teeth with necrotic pulps. Two case reports are presented in which teeth with large open apices and immature roots were clinically managed by placing demineralised freeze-dried bone allograft (DFDBA) as a matrix before placement of Mineral Trioxide Aggregate (MTA) as an apical barrier. The indications for and advantages of using DFDBA and MTA are discussed.

\section{INTRODUCTION}

The field of endodontics poses numerous challenges, amongst which is the management of the immature tooth with incomplete root development. ${ }^{1-2}$ In these situations, the absence of a natural constriction at the end of the root canal makes control of obturation materials difficult. ${ }^{3}$ Root canal rehabilitation is a significant challenge, because of the size of the canal, the thin and fragile dentine walls and the large open apex. Other challenges include instrumentation techniques, correct length determination and adequate irrigation. There is also a high risk of root

1. Casper H Jonker: BChD, Dip.Odont, Msc. (Pret.). Module of Endodontics. Department of Operative Dentistry, School of Oral Health Sciences, Sefako Makgatho Health Sciences University, Gauteng, South Africa.

2. Peet J van der Vyver: $B C h D$, Dip.Odont, Msc. (Pret.) Department of Odontology, School of Dentistry, University of Pretoria, Pretoria, South Africa and Private Practice, Sandton, South Africa.

\section{Corresponding author}

\section{Casper H Jonker:}

Module of Endodontics, Department of Operative Dentistry, School of

Oral Health Sciences, Sefako Makgatho Health Sciences University,

Gauteng, South Africa. E-mail: casper.jonker@smu.ac.za

\section{ACRONYMS}

DFDBA: demineralised freeze-dried bone allograft

DMBM: demineralised bone matrix

DOM: dental operating microscope

MAP: Micro-Apical Placement System

MTA: Mineral Trioxide Aggregate

fracture and it has traditionally been considered that teeth with incomplete root development and wide open apices have poorer prognoses and even the best endodontic treatments have a high possibility of failure. ${ }^{1,2,4}$

Apexification is a method aimed at inducing a calcified barrier at the root tip of a tooth with an open apex or encouraging the continued apical development of an incomplete root in a tooth with a necrotic pulp. ${ }^{5}$ Apart from allowing compaction of the obturation material, the goal of this treatment includes obtaining an apical barrier to prevent the extrusion of toxins and bacteria into the periapical tissues from the root canal. The procedure of chemically or mechanically creating an apical barrier is therefore defined as "apexification". ${ }^{6}$

Several materials - including calcium hydroxide paste, calcium hydroxide powder and other alternatives - have been used in the past in an effort to create the apical barrier. ${ }^{7-15}$ Attempts have also previously been made to utilize a mixture of materials and chemicals in an effort to stimulate apexification and natural root closure. ${ }^{16} \mathrm{Ham}$ et al. (1972) treated immature pulpless teeth in monkeys by cleaning and shaping with endodontic instruments beyond the root apex in an effort to induce bleeding to allow the formation of a blood clot in the hope of stimulating natural root closure. ${ }^{17}$ Traditionally, the material of choice 


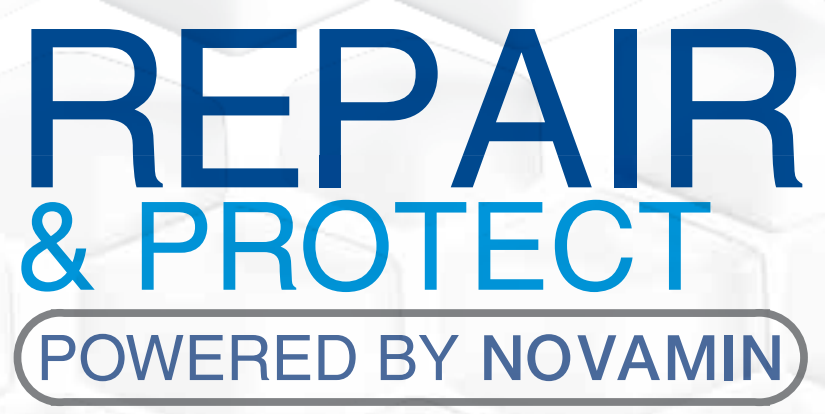

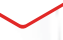

\section{N \\ DENTIST RECOMMENDED BRAND FOR SENSITIVE TEETH ${ }^{\star}$}

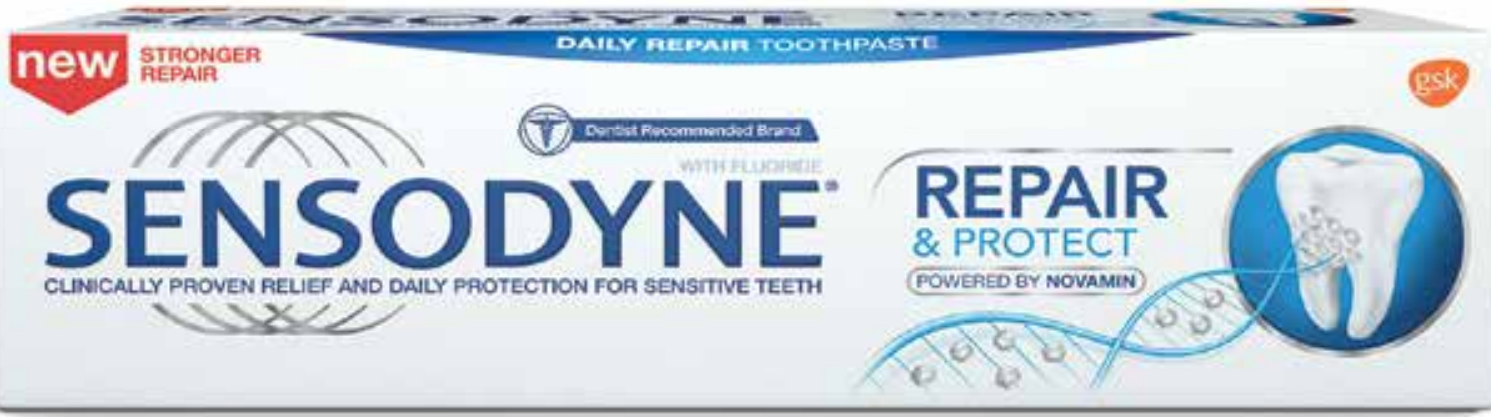


has been calcium hydroxide to stimulate the formation of the apical barrier, but the procedure involves numerous appointments and the treatment phase regularly extends over six months. ${ }^{18,19}$ Major disadvantages of prolonged contact with calcium hydroxide is that a significant decrease occurs in the intrinsic properties of exposed dentine and that immature roots become more susceptible to vertical root fractures. ${ }^{18}$

The development of MTA provided a breakthrough in the field of endodontics and offered a most acceptable substitute for calcium hydroxide in the creation of an apical barrier. This material has advantages which include reduced chair time, a favourable outcome in the healing of periapical lesions and resolution of clinical symptoms. ${ }^{20-23}$

In certain scenarios, an apical matrix is needed to provide sufficient resistance for the apical compaction of MTA and to avoid extensive overfill of the material. Bio-resorbable demineralised bone matrix (DMBM) is the protein component of bone and can be considered as a viable material from which to create the apical plug. DMBM has been widely used in other disciplines of dentistry in the treatment of periodontal and maxillofacial bone defects. Histological studies have shown favourable healing of bone and neighbouring periodontium when demineralised bone was used in the treatment of periodontal defects. ${ }^{24,25}$ The osteo-conductive potential of this material makes it suitable for the creation of the apical barrier before MTA placement.

This article presents two detailed case reports on the use of a novel matrix such as DFDBA prior to placement of MTA as an apical barrier.

\section{CASE REPORT 1}

A 21-year-old male complaining of discomfort on his upper right central incisor received emergency root canal treatment at a Dental Clinic and was then referred to the Department of Operative Dentistry at Sefako Makgatho Oral Health Centre, Ga-Rankuwa, South Africa. The patient presented with an uncomplicated medical history. A history of dental trauma was noted but the exact date was unknown. On examination discolouration of the upper right central incisor was noted and a draining fistula was observed on the buccal mucosa in the region of the apex of the tooth. Slight tenderness was elicited on palpation around the apical region. On thermal stimulation, no response was recorded. The tooth was diagnosed as presenting with a necrotic

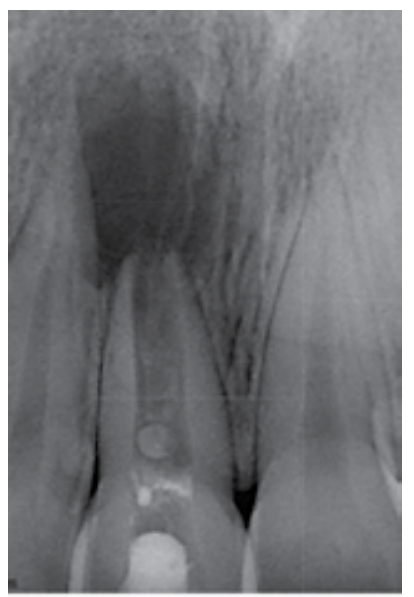

Figure 1: Pre-operative radiograph showing an incomplete root closure, open apex and a large periapical lesion pulp and a periapical chronic abscess. The pre-operative radiograph revealed an incomplete root closure, open apex and a large periapical lesion (Figure 1).

Two treatment possibilities were offered to the patient: the revascularisation procedure or non-surgical endodontics with an apexification using MTA (ProRoot MTA, Dentsply Sirona, Switzerland) and DMBM. Consent was obtained for the latter option after a detailed discussion with the patient, and based on the predictability of the procedure. A rubber dam was placed and an access cavity was prepared. Once the canal was opened, no drainage could be observed, but a pervasive necrotic odour was noted. Length determination was accomplished using Machtou pluggers (Denstply Sirona) and estimated at $19,5 \mathrm{~mm}$ with the incisal edge as a reference point (Figure 2).

The root canal was

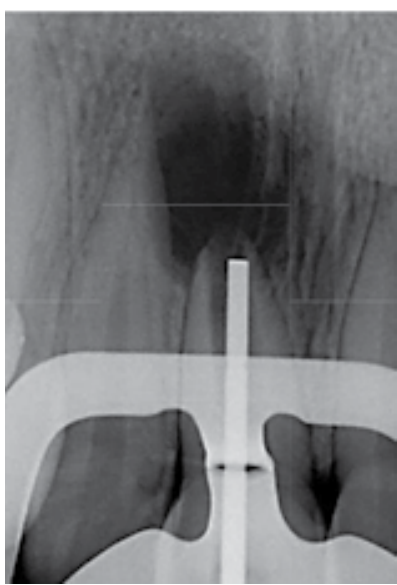

Figure 2: Length determination using a Machtou plugger

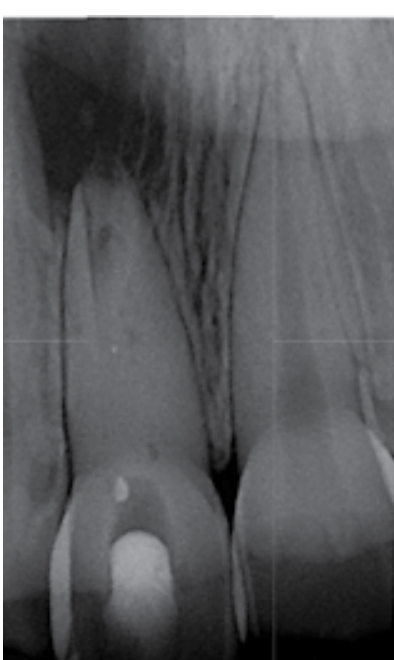

Figure 3: Calcium hydroxide paste (Calacept Plus) and temporary Ketac was Molar restoration chemically disinfected with $3.5 \%$ sodium hypochlorite, excess fluids from the root canal were removed with paper points and an intracanal medicament of calcium hydroxide paste was placed (Calasept Plus, Nordiska Dental, Sweden) (Figure 3).

The tooth was sealed with Ketac Molar (3M ESPE) as a temporary restoration and post-operative instructions were provided. The patient was scheduled for his next appointment four weeks later.

On the second visit, it was noted that the draining fistula had disappeared. The patient reported no symptoms. No drainage from the canal was visible and the intracanal medicament was removed by irrigation with 3.5\% sodium hypochlorite. Chemicals and excess fluids were removed from the root canal with paper points. A mixture of DFDBA (Osseograft TM, Advanced Biotech Products) (Figure 4) and sterile water was prepared. The mixture was placed in the coronal portion of the root canal and manipulated apically and beyond the apex with the Machtou pluggers, ensuring that an apical plug was established at the working length with resistance sufficient 


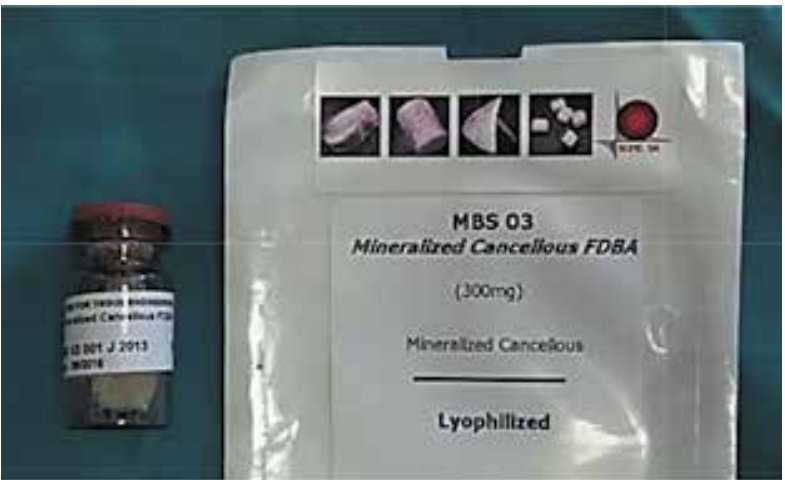

Figure 4: Decalcified freeze-dried bone allograft

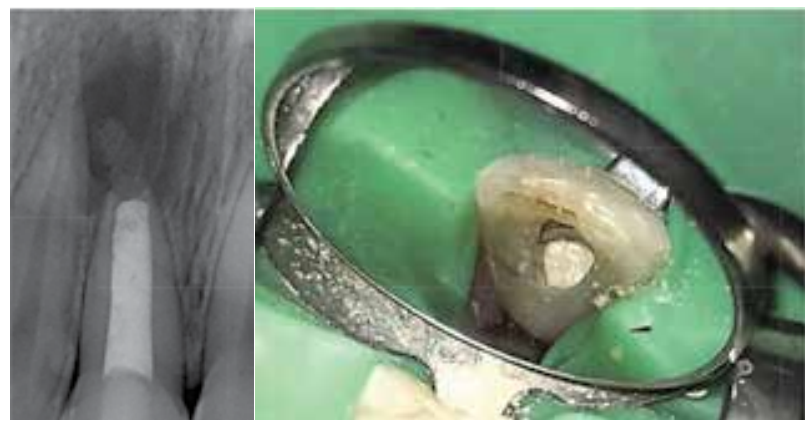

to create a proper barrier for MTA. Visual accuracy was enhanced by the use of the Dental Operating Microscope (DOM). A small quantity of white MTA (Dentsply Sirona) was placed in the canal and moved apically with the use of large paper points and Machtou pluggers (Denstply Sirona). The decision was then made to fill the complete root canal space with MTA (Figures $5 a$ and b).

At a follow-up consultation and evaluation four weeks later, it was observed that there was no visible swelling, there were no clinical symptoms on percussion and palpation of the tooth, and no mobility could be demonstrated. The patient was re-scheduled for an eight-month follow-up at which time notable bone healing with a reduction in diameter of the periapical lesion was seen (Figure 6). On a 12-month post-operative follow-up visit, examination of a periapical radiograph confirmed clear signs of bone healing and reduction of the large apical radiolucency (Figure 7).

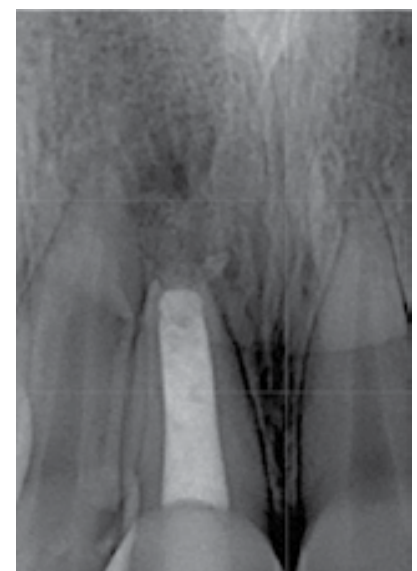

Figure 6: Periapical radiograph at the 8-month follow-up visit

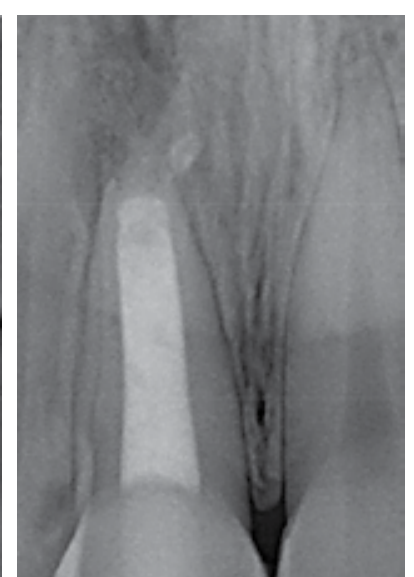

Figure 7: Periapical radiograph at the 12-month follow-up visit

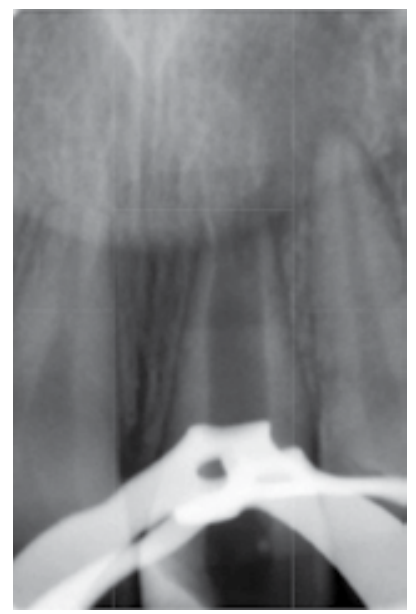

Figure 8: Pre-operative radiograph showing an incomplete root closure, open apex and a small periapical lesion

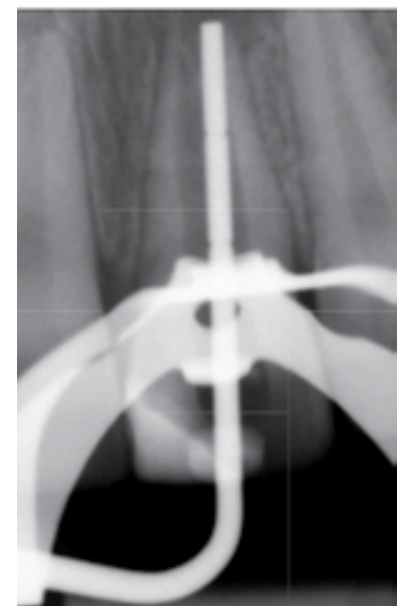

Figure 9: Radiographic confirmation of the working length using a Machtou plugger connected to an electronic apex locator

\section{CASE REPORT 2}

A 17-year-old male presented in private practice with a history of previous dental trauma to his maxillary right central incisor about nine years previously. A pre-operative periapical radiograph revealed incomplete root closure associated with a wide-open apex and a large periapical lesion (Figure 8). After placement of a rubber dam an access cavity was prepared. Length determination was accomplished using Machtou pluggers (Denstply Sirona) and an electronic apex locator (Pixie Electronic Apex Locator, Dentsply Sirona). The working length was confirmed radiographically (Figure 9).

Remnants of the root canal contents were removed with Profile 04/90 instrument (Dentsply Sirona) before the canal was chemically disinfected with pre-heated (approximately 55 degrees Celsius) $3.5 \%$ sodium hypochlorite for five minutes. Calcium hydroxide paste was placed (Ultracal, Ultradent, Utah, USA) as an intra-canal medicament.

At the second visit, two weeks later, the medicament was removed by activating $3.5 \%$ sodium hypochlorite with an Endo-Activator (Dentsply Sirona). Excess fluids were removed from the root canal using ISO size 100 paper points under DOM magnification. A mixture of DFDBA (Osseograft TM, Advanced Biotech Products) (Figure 4) and sterile water was prepared at the chairside. The mixture was placed in the coronal portion of the root canal and then manipulated apically and beyond the apex with the Machtou pluggers under the DOM, until resistance was felt at the point of the predetermined working length. White MTA (Dentsply Sirona) was then mixed according to the manufacturer's instructions and dispensed into the canal with the use of the Micro-Apical Placement System (MAP) system (Dentsply Maillefer). The dispensed MTA was moved apically against the apical matrix using the Machtou pluggers. A plug of approximately $3 \mathrm{~mm}$ was created against the matrix in the apical part of the root canal and placement was checked radiographically (Figure 10). Another $2 \mathrm{~mm}$ of additional MTA was packed in to create a $5 \mathrm{~mm}$ apical plug before the canal was obturated with Pulp 
Canal Sealer (Kerr Corporation, Orange, Ca, USA) and warm gutta-percha dispensed from an Obtura II unit (Obtura Spartan, IL, USA)(Figure 11).

The patient attended an eight-month follow-up visit when the tooth was permanently restored. A periapical radiograph showed complete apical healing (Figure 12).

\section{DISCUSSION}

In both cases, calcium hydroxide was used as an intra-canal medicament to achieve sterility in the root canal systems. It appears that a maximum period of up to four weeks is clinically acceptable before structural changes can be seen in the root dentine, which could lead to an increased susceptibility to fractures of the prepared roots. ${ }^{18,26}$ It has been shown that time is needed for hydroxyl ions to diffuse from the inner- to the outer dentine surface in order to reach an appropriate $\mathrm{pH}$ level. ${ }^{27} \mathrm{~A}$ risk of root fracture does, therefore exist with longer periods of calcium hydroxide as an intra-canal antibacterial medium. ${ }^{18}$

In the past, DFDBA material formed a decisive part of treatment approaches when an periodontist was confronted with periodontal bone defects. This approach has resulted in a proven reduction of clinically unacceptable periodontal pocket depths, with accompanying increased stability of the tooth and enhanced health of clinical attachment and the neighbouring periodontium. ${ }^{28,29}$ These studies further reported that radiographs taken at follow-up consultations demonstrated healing in the affected areas with the periapical pathology showing signs of resolution. An additional benefit of using freezedried demineralised bone is that it serves as an osteoconductor and even has the potential to induce bone formation. ${ }^{25,30}$ It could be speculated, but not yet proven, that it might have played a role in stimulating bone healing in our case but its primary use was to form a mechanical barrier for the placement and condensation of MTA. In the treatment option adopted in this case, the DFDBA provided sufficient resistance to withstand vertical compaction of MTA without accidental overfill of MTA into the periapical area. The decision was made to avoid further extrusion of bone particles once adequate resistance was encountered rather than forcing more particles beyond the apex and risking damage to the root canal walls.

The use of MTA in the apexification procedure provides an excellent treatment option in the management of teeth that present with incomplete root and apex formation and has the advantage of reduced chair time. Calcium hydroxide, by comparison, requires a number of appointments to stimulate barrier formation. ${ }^{18,19}$ Apatitelike interfacial deposits can be observed in the maturation phase of MTA, very similar to a primary monoblock. The deposits fill any possible voids encountered during the

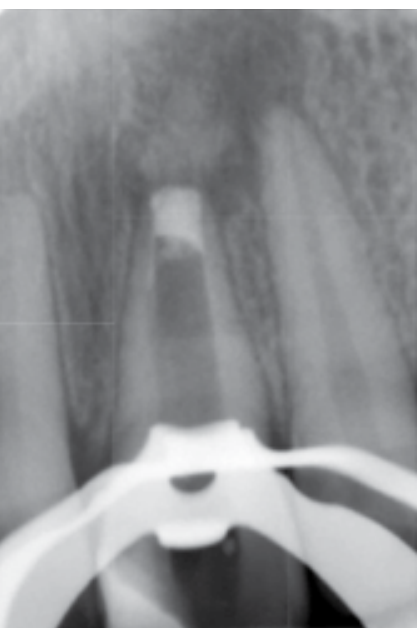

Figure 10: Periapical radiograph showing the apical barrier and the $3 \mathrm{~mm}$ apical MTA plug

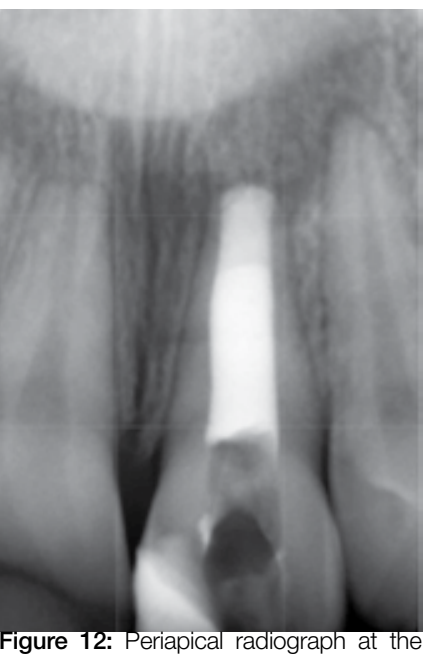
-month follow-up visit showing good pical healing

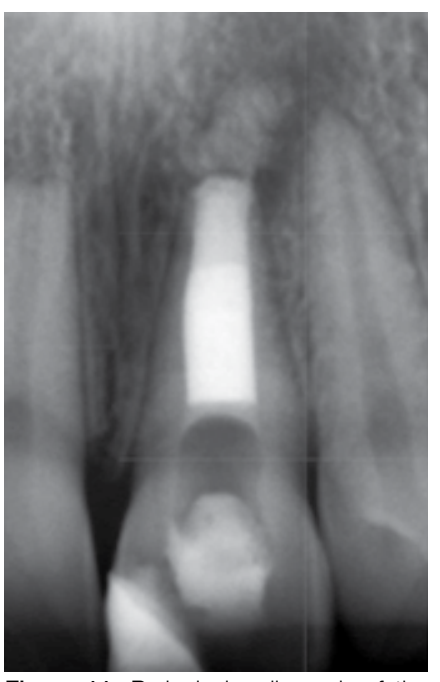

Figure 11: Periapical radiograph of the immediate postoperative result

setting/shrinkage phase and also increase the frictional resistance between MTA and the root canal walls. It can be speculated that the formation of these apatite deposits is responsible for the superior seal created by MTA when it is used as a regular obturation material during standard root canal treatment and for the repair of root canal perforations. ${ }^{31}$

The numerous additional advantages offered by MTA include superb biocompatibility, a biologically acceptable seal and reduced cytotoxicity compared with alternative materials used in the treatment of the pulp. ${ }^{32}$ It has been advocated that a minimum barrier of approximately $5 \mathrm{~mm}$ MTA is needed to guarantee strength and reduce micro-leakage. It could be argued that the affected tooth in case report One above could then have been treated with an apical MTA barrier of $5 \mathrm{~mm}$ and standard obturation with gutta-percha in the remaining coronal part of the root canal. It has been shown that obturation with gutta-percha does not increase resistance to root fractures, which may occur even with low forces. ${ }^{33}$ A review study conducted by Bogen and Kuttler in 2009 concluded that the use of MTA to obturate the complete root canal system might ultimately increase the long-term prognosis and retention of the tooth compared with the use of conventional obturation methods in conventional and complex therapies. ${ }^{34}$

The results obtained in these clinical case reports suggest that there are clear advantages in the single-visit apexification procedure in the management of large open apices in trauma-affected teeth. 


\section{References}

1. Trope M. Treatment of the immature tooth with a non-vital pulp and apical periodontitis. Dent Clin North Am. 2010; 54: 313-24.

2. Cvek M. Prognosis of luxated non-vital maxillary incisors treated with calcium hydroxide and filled with gutta-percha. A retrospective clinical study. Endod Dent Traumatol. 1992; 8: 45-55.

3. Seltzer S. Endodontology: Biologic Considerations in Endodontic Procedures, 2nd edn. Philadelphia: Lea \& Febiger, 1988.

4. Jeeruphan T, Jantarat J, Yanpiset $\mathrm{K}$, et al. Mahidol study 1: comparison of radiographic and survival outcomes of immature teeth treated with either regenerative endodontic or apexification methods: a retrospective study. J Endod. 2012; 38: 1330-6.

5. American Association of Endodontists Glossary of Endodontic Terms, 7th edn. Chicago: American Association of Endodontists, 2003.

6. Alobaid A, Cortes L, Lo J, Nguyen T, Albert J, Abu-Melha A, Lin L, Gibbs J. Radiographic and clinical outcomes of the treatment of immature permanent teeth by revascularization or apexification: A pilot retrospective cohort study. J Endod. 2014; 40: 1063-70.

7. Michanowicz JP, Michanowicz AE. A conservative approach and procedure to fill an incompletely formed root using calcium hydroxide as an adjunct. J Dent Child. 1967; 34: 42-7.

8. Pitts DL, Jones JE, Oswald RJ. A histological comparison of calcium hydroxide plugs and dentin plugs used for the control of guttapercha root canal filling material. J Endod. 1984; 10: 283-93.

9. Schumacher JW, Rutledge RE. An alternative to apexification. J Endod. 1993; 19: 529-31.

10. Coviello J, Brilliant JD. A preliminary clinical study on the use of tricalciumphosphate as an apical barrier. J Endod. 1979; 5: 6-13.

11. Nevins A, Finkelstein F, Laporta R, Borden BG. Induction of hard tissue into pulpless open-apex teeth using collagen-calcium phosphate gel. J Endod. 1978; 4: 76-81.

12. Dimashkieh MR. A method of using silver amalgam in routine endodontics, and its use in open apices. Br Dent J. 1975; 138: 298-300.

13. Eleazer PD, McDonald TW, Sinai IH, Fantasia JE, Michelich RJ, Yagiela JA. Proplast as an apical barrier in root canal therapy. J Endod. 1984; 10: 487-90.

14. Narang $R$, Wells $H$. Experimental osteogenesis in periapical areas with decalcified bone matrix. Oral Surg Oral Med Oral Pathol Oral Radiol Endod. 1973; 35: 136-43.

15. Yoshida T, Itoh T, Saitoh T, Sekine I. Histopathological study of the use of freeze-dried allogenic dentin powder and True Bone Ceramic as apical barrier materials. J Endod. 1998; 24: 581-6.

16. Thibodeau B, Trope M. Pulp revascularization of a necrotic infected immature permanent tooth: Case report and review of the literature. Pediatr Dent. 2007; 29: 47-50.

17. Ham JW, Patterson SS, Michell DF. Induced apical closure of immature pulpless teeth in monkeys. Oral Surg Oral Med Oral Pathol Oral Radiol Endod. 1972; 33: 438-49.

18. Andreasen JO, Farik B, Munksgaard EC. Long-term calcium hydroxide as a root canal dressing may increase risk of root fracture. Dent Traumatol. 2002; 18: 134-7.

19. Sheehy EC, Roberts GJ. Use of calcium hydroxide for apical barrier formation and healing in non-vital immature permanent teeth: a review. Br Dent J. 1997; 183: 241-6.

20. Holden DT, Schwartz SA, Kirkpatrick TC, Schindlier WG. Clinical outcomes of artificial root-end barriers with mineral trioxide aggregate in teeth with immature apices. J Endod. 2008; 34: 812-7.
21. Moore A, Howley MF, O'Connell AC. Treatment of open apex teeth using two types of white mineral trioxide aggregate after initial dressing with calcium hydroxide in children. Dent Traumatol. 2011; 27: 166-73.

22. El-Meligy OA, Avery DR. Comparison of mineral trioxide aggregate and calcium hydroxide as pulpotomy agents in young permanent teeth (apexogenesis). Pediatr Dent. 2006; 28: 399-404.

23. Pradhan DP, Chawla HS, Gauba K, Goyal A. Comparative evaluation of endodontic management of teeth with unformed apices with mineral trioxide aggregate and calcium hydroxide. J Dent Child (Chic). 2006; 73: 79-85.

24. Mellonig JT. Bone Allografts in periodontal therapy. Clin Orthop Relat Res. 1996; 324: 116-25.

25. Meadows CL, Gher ME, Quintero G, Laferty TA. A comparison of polylactic acid granules and decalcified freeze dried bone allograft in human periodontal osseous defects. J Periodontol. 1993; 64: 103-9.

26. Hatibovic-Kofman S, Raimundo L, Zheng L. Fracture resistance and histological findings of immature teeth treated with mineral trioxide aggregate. Dent Traumatol. 2008; 24: 272-6.

27. Nerwich A, Figdor D. Messer H. PH changes in root dentin over a 4-week period following root canal dressing with calcium hydroxide. J Endod 1993; 19: 302-6.

28. Mellonig JT. Freeze dried bone allografts in periodontal reconstructive surgery. Dent Clin North Am Reconstr Periodont. 1991; 35: 505-20.

29. Hiremath H, Gada N, Kini Y, Kulkarni S, Akub SS, Metgud S. Single step apical barrier placement in immature teeth using mineral trioxide aggregate and management of periapical inflammatory lesion. J Endod. 2008; 40: 1020-24.

30. Finkemeier CG. Bone-grafting and bone-graft substitutes. J Bone Joint Surg Am. 2002; 84: 454-64.

31. Tay FR, Pashley DH. Monoblocks in root canals: A hypothetical or a tangible goal. J Endod. 2007; 33: 391-8.

32. Schmitt D, Lee J, Bogen G. Multifaceted use of ProRoot MTA root canal repair material. Pediatr Dent. 2001; 23: 326-30.

33. Hammad M, Qualtrough A, Silikas N. Effect of new obturating materials on vertical root fracture resistance of endodontically treated teeth. J Endo. 2007; 33: 732-36.

34. Bogen G, Kuttler S. Mineral Trioxide Aggregate Obturation: A Review and Case Series. J Endod. 2009; 35: 777-90. 